\title{
Sugar Beet Growing in East Anglia.'
}

$\mathrm{D}^{\mathrm{t}}$

ESPITE the fact that there were 222,000 acres under sugar beet in Great Britain in 1927, the crop must still be regarded as being on trial. The rapid increase in its acreage is due in large part to the action of the temporary subsidy on home-grown sugar, and we have still to learn whether it will take its place as a considerable factor in British agriculture of the future. The amount of trustworthy information about the crop in its various aspects is still quite small, and therefore the recently published work on the sugar beet crop in the eastern counties of England during 1927 from the Farm Economies Branch of the Department of Agriculture of the University of Cambridge has an added value.

The conduct of a close investigation, covering 100 farms and some 2300 acres, situated in eleven counties, must always be a matter which requires daring in conception and steady perseverance in execution. The Cambridge team has attacked the business in a pioneering spirit, and where the standard methods of agricultural costing have not met new requirements, they have been modified to suit the occasion. The results, which form the investigation of what is described as the "largest sample that has ever been made," are bound to be interesting, and both interest and confidence increase when it is realised that each of the stages of the work has been handled with care and common sense.

The final tables upon which the whole of the detailed work converges show that the average yield obtained on the land under consideration was $7 \cdot 711$ tons per acre of washed beet, and that the average net cost of this to the grower was $£ 2: 4: 5 \frac{1}{2}$ per ton, or $£ 17: 2: 8 \frac{3}{4}$ per acre, and this is worked down to a standard error of mean net cost of only $5 s .6 d$. per

1 "Sugar Beet in the Eastern Counties, 1927 : being an Investigation into the Financial Results obtained on One Hundred Farms, and some of the Factors influencing them." By R. McG. Carslaw, C. Burgess, G. Ll. Rogers. (University of Cambridge, Department of A griculture, Farm Economics Branch, Report No.9.) Pp. xii +94 . (Cambridge: W. Heffer and Sons, Ltd., 1928.) 3s. net. acre. The extremes of cost over the 182 fields involved situated on many different soils vary from $£ 10$ per acre to $£ 31$ per acre, and these point to the fact that the individual accounts in the appendices should be studied in conjunction with the averages before conclusions are drawn about any one type of farm or class of soil as being suitable for sugar beet.

From the climatic point of view 1927 was not a good season for sugar beet, and 7.711 tons per acre is not a good yield, though it exceeds the national average for that year by about 1 ton. Despite this, the average net profit shown in the investigation was $£ 4: 4: 1$ per acre, or $10 s .10 \frac{3}{4} d$. per ton. Of this net profit, by far the larger part, $£ 3: 18: 7 \frac{1}{2}$, is represented by credits to the crop for tops, residual value of manures, and extra cultivations, and in this light the crop appears as one which enables the arable farmer to get his expensive cleaning shift for nothing, rather than as one which brings a large cash supplement to his bank account. The main factor in deciding the cost per ton of washed beet on the various holdings involved has been, of course, the yield per acre, and the first result of this investigation is to point to the need for higher average yields if sugar beet is to flourish as a real cash crop, and not to languish as a cleaning crop rather less expensive than swedes or mangolds.

The design of the investigation has allowed for the examination of a number of the steps taken by growers in producing the crop, and some figures are produced which throw a new and sometimes surprising light on the value of such things as farmyard manure, subsoiling, rates of seeding, and field spacing. These figures, while they cannot be considered as the basis for final dicta, are of real interest to growers of the crop.

It is satisfactory to know that the investigation is being continued in the present year, and that there will be a second set of results to test and add value to those already published.

\section{Salmon Disease.}

TURUNCULOSIS, an epizootic disease causing considerable mortality among salmon and trout from time to time, has only recently spread into Scotland and the north of England, though it was known in central Europe so long ago as 1894 . It has been investigated independently in Great Britain by Dr. F. H. A. Clayton (Rep. Dove Marine Lab., New Series, 16, p. 49; 1927) and Miss Isobel J. F. Williamson (Fishery Board for Scotland, Salmon Fisheries, No. 5, 1928. H.M. Stationery Office, 1s. $3 d$. net.)

Miss Williamson finds that the characteristic superficial lesions ('furuncles') are areas of subcutaneous necrosis, not comparable to the pus-producing lesions of warm-blooded vertebrates. Both authors obtained similar results by inoculation of experimental animals, such as brown trout, salmon and sea-trout smolts, blenny and plaice (Clayton), frogs, trout, and other fishes (Williamson). Inoculation through the open mouth and direct application of the culture to scarified areas of skin proved pathogenic to trout and other species, which died in one to four weeks, and the causative bacillus, $B$. salmonicida Emmerlich and Weibel, was recovered from the heart-blood. Characteristic symptoms were observed, including the furuncles and the loss of orientation shortly before death (Williamson). Infection of the water was longer in taking effect. Both authors infected salt-water fish, and whereas Miss Williamson recovered $B$. salmonicida in a Zoarces which died from other causes, Dr. Clayton found the disease lethal to the same fish.

Dr. Clayton makes an important contribution to the subject by his discovery that one of two codling, internally inoculated, harboured the bacillus for at least a month in perfect health, and points out that an immune or partially immune sea-going salmon might act as a carrier, and introduce the disease into other rivers, since it is now known that the salmon does not always return to its native river to spawn. In culture the organism appears to be less viable in salt than in fresh water, and Miss Williamson's experiments with polluted natural waters from various sources have failed to reveal any connexion between these conditions and the spread of the disease. Her view is shared by Dr. Clayton, and both point out its common occurrence in rivers like the Coquet and upper tributaries of the Tay, where there could be no question of pollution. That furunculosis is spread by immune individuals or 'carriers' seems to be the most probable explanation.

No. 3087 , VoL. 122] 